\title{
Microfluidically supported characterization of responses of Rhodococcus erythropolis strains isolated from different soils on $\mathrm{Cu}-, \mathrm{Ni}-$, and Co-stress
}

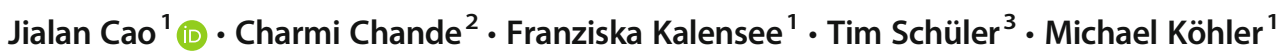

Received: 9 November 2020 / Accepted: 8 April 2021 / Published online: 6 May 2021

(C) The Author(s) 2021

\begin{abstract}
We present a new methodological approach for the assessment of the susceptibility of Rhodococcus erythropolis strains from specific sampling sites in response to increasing heavy metal concentration $\left(\mathrm{Cu}^{2+}, \mathrm{Ni}^{2+}\right.$, and $\left.\mathrm{Co}^{2+}\right)$ using the droplet-based microfluid technique. All isolates belong to the species R. erythropolis identified by Sanger sequencing of the 16S rRNA. The tiny step-wise variation of metal concentrations from zero to the lower $\mathrm{mM}$ range in $500 \mathrm{~nL}$ droplets not only provided accurate data for critical metal ion concentrations but also resulted in a detailed visualization of the concentration-dependent response of bacterial growth and autofluorescence activity. As a result, some of the isolates showed similar characteristics in heavy metal tolerance against $\mathrm{Cu}^{2+}, \mathrm{Ni}^{2+}$, and $\mathrm{Co}^{2+}$. However, significantly different heavy metal tolerances were found for other strains. Surprisingly, samples from the surface soil of ancient copper mining areas supplied mostly strains with a moderate sensitivity to $\mathrm{Cu}^{2+}, \mathrm{Ni}^{2+}$, and $\mathrm{Co}^{2+}$, but in contrast, a soil sample from an excavation site of a medieval city that had been covered for about eight centuries showed an extremely high tolerance against cobalt ion (up to $36 \mathrm{mM}$ ). The differences among the strains not only may be regarded as results of adaptation to the different environmental conditions faced by the strains in nature but also seem to be related to ancient human activities and temporal partial decoupling of soil elements from the surface. This investigation confirmed that microfluidic screening offers empirical characterization of properties from same species which has been isolated from sites known to have different human activities in the past.
\end{abstract}

Keywords Droplet-based microfluidics $\cdot$ Dose-response $\cdot$ Rhodococcus $\cdot$ Heavy metals $\cdot$ Intraspecies differences $\cdot$ Copper mining

\section{Introduction}

Closed-loop processes are one of the most important challenges for a sustainable material management. The conversion of toxic substances into environmental-compatible species is

Responsible Editor: Luc F.M. Rouws

Jialan Cao

jialan.cao@tu-ilmenau.de

1 Institute for Micro- and Nanotechnologies/Institute for Chemistry and Biotechnique, Department of Physical Chemistry and Microreaction Technology, Technical University Ilmenau, PF 1005 6598684 Ilmenau Germany

2 Department of Chemical and Materials Engineering, New Jersey Institute of Technology, Newark, NJ 07102, USA

3 Thuringian State Office for Monument Preservation and Archeology (TLDA), Humboldtstr.11, 99423 Weimar, Germany an important step in the process chain from weed out of technical products to the re-feeding into natural biological systems [1]. Microorganisms are the main players in these conversion processes [2]. It is to assume that in future, such biotechnological conversions will completely substitute hightemperature treatment and other chemical processes for material conversion.

Among the numerous of microorganisms, the genus Rhodococcus has attracted a lot of interest during the last decades due to the ability of several strains for bioremediation of phenol-, dye-, fuel-, or solvent-contaminated soils [3-6]. The genus is strictly aerobic and heterotroph. It belongs to the family Nocardiaceae in the phylum Actinobacteria. Bacteria as $R$. erythropolis can promote the bioremediation by direct utilization of organic contaminants as well as by supporting the bioflocculation process [7]. The $R$. erythropolis strain IBBPol, for example, is able to utilize not only aliphatic compounds as n-hexane, cyclohexane, and decane but also aromatic solvents and monomers as toluene, 
ethylbenzene, and styrene [8]. Thus, Rhodococcus is of interest for the degradation of crude oil [9], is usable for the desulfurization of fuels [10], and can also play an important role in the bio-recycling of lignocellulose, which is very crucial for the usage of renewable materials [11]. There are known Rhodococcus strains which are able to grow under extreme $\mathrm{pH}$ conditions or high salt content [12]. On the other hand, several $R$. erythropolis strains can tolerate and accumulate metal ions [13], among them chromate [14] and other toxic metals such as $\mathrm{Zn}$ and $\mathrm{Cd}$ [15] which could be involved in metalloprotein with biocatalytic properties. Furthermore, Rhodococcus can be applied for the production of biosurfactants $[16,17]$ and for the transformation of terpenes usable in the production of fragrances [18] and in the modification of steroids, which is important for drug production [19].

There is an urgent need to develop new and more efficient methods for the search of new bacterial strains with new remediation features and biosynthesis capabilities [20]. Beside the isolation of new strains, the investigation on tolerances against toxic organic substances and metals are promising directions for future screening processes. Thus, the ability of microorganisms to accumulate metals and to use the metals as co-factor of enzymes (e.g., superoxide dismutase) to degrade pollutants can be characterized. Microfluidic techniques are promising tools in order to overcome this multiparameter screening challenge. The key issue of the application of microfluidic for the cultivation of microorganisms is miniaturization, the separation of closed cultivation compartments and the realization of a high-throughput screenings. Furthermore, miniaturized microfluidic systems provide better precision in generating multiple concentrations and low sample volume for operation (sub-microliter or nanoliter range) compared to conventional macroscopic culture systems such as microtiter plates and Petri dishes. The determination of highly resolved dose-response functions is an attractive strategy compared to traditional studies in which only a few larger intervals of concentration steps can be investigated [21]. Among the microfluidic techniques, the technique of micro segmented flow [22] is well suited for an efficient characterization of microorganisms [23], heavy metal-tolerant soil bacterial [24], soil microbial communities [25, 26], as well as for eukaryotic [27] and multicellular microorganisms [28].

The co-contamination of soils by organic components and heavy metals on the one hand and essential functions of metals and metal accumulation for the synthesis and operation of special enzymes, on the other hand, makes the evaluation of metal tolerances of Rhodococcus strains particularly interesting [29]. In this work, micro segmented flow technique was implemented to evaluate the heavy metal tolerance of ten strains of $R$. erythropolis isolated from eight soil samples, whereby seven were taken from an ancient mining area and one probe taken from a metal-contaminated archeological site. In contrast to other microfluidic techniques, the method of micro segmented flow combines a strict separation of small cultivation volumes - typically in the $\mathrm{nL}$ and sub- $\mu \mathrm{L}$ range - with an accurate automatic variation of effector concentrations in small concentration steps. At the same time, a safe storing of the different cultivation volumes in the original order is provided. This allows a reliable addressing of individual effector concentrations in the single droplets and keeps the information about this concentration over the complete incubation phase. The method supplies highly resolved doseresponse functions from microfluidic screenings. Here, we investigate their applicability and potential for distinguishing different strains of the same species by their sensitivity against copper, cobalt, and nickel.

\section{Materials and methods}

Declaration: the authors declare that all procedures of these studies were performed according to the laws enforced in Germany.

\section{Chemicals}

For the preselection cultivation, three different culture media, actinimyceten minimal medium (AM), soil extract medium (SEM), and VL55 medium, were utilized. The AM minimal medium consisted of $0.5 \mathrm{~g} / \mathrm{L}$ asparagine, $0.5 \mathrm{~g} / \mathrm{L} \mathrm{K}_{2} \mathrm{HPO}_{4}, 0.2$ $\mathrm{g} / \mathrm{L} \mathrm{MgSO}_{4} \cdot 7 \mathrm{H}_{2} \mathrm{O}, 0.01 \mathrm{~g} / \mathrm{L} \mathrm{FeSO}_{4} \cdot 7 \mathrm{H}_{2} \mathrm{O}$, and $10 \mathrm{~g} / \mathrm{L}$ glucose monohydrate. The $\mathrm{pH}$ value of the $\mathrm{AM}$ media was adjusted to $\mathrm{pH}$ 6.8. The SEM medium was prepared as followed: $1000 \mathrm{ml}$ distilled water was added with $666 \mathrm{~g}$ of air-dried soil and allowed to sediment for $3 \mathrm{~h}$ at room temperature. Thereafter, the supernatant was centrifuged at $1920 \times \mathrm{g}$ for $5 \mathrm{~min}$ and passed through a $0.22 \mu \mathrm{m}$ filter. Followed by $0.5 \mathrm{~g} / \mathrm{L}$ asparagine, $0.5 \mathrm{~g} / \mathrm{L} \mathrm{K} \mathrm{HPO}_{4}, 0.2 \mathrm{~g} / \mathrm{L} \mathrm{MgSO}{ }_{4} \cdot 7 \mathrm{H}_{2} \mathrm{O}, 0.01 \mathrm{~g} / \mathrm{L}$ $\mathrm{FeSO}_{4} \cdot 7 \mathrm{H}_{2} \mathrm{O}$, and $10 \mathrm{~g} / \mathrm{L}$ glucose were added to the soil extract. The VL55 medium consisted of $1.95 \mathrm{~g} / \mathrm{L}$ 2-morpholino ethanesulfonic acid, $49.3 \mathrm{mg} / \mathrm{L} \mathrm{MgSO}{ }_{4} \cdot 7 \mathrm{H}_{2} \mathrm{O}, 44.1 \mathrm{mg} / \mathrm{L}$ $\mathrm{CaCl}_{2} \cdot 2 \mathrm{H}_{2} \mathrm{O}, 26.4 \mathrm{mg} / \mathrm{L}\left(\mathrm{NH}_{4}\right)_{2} \mathrm{HPO}_{4}, 1 \mathrm{ml} / \mathrm{L}$ selenitetungstate solution $\left(0.5 \mathrm{~g} / \mathrm{L} \mathrm{NaOH}, 3 \mathrm{mg} / \mathrm{L} \mathrm{Na}_{2} \mathrm{SeO}_{3} \cdot 5 \mathrm{H}_{2} \mathrm{O}, 4\right.$ $\left.\mathrm{mg} / \mathrm{L} \mathrm{Na}_{2} \mathrm{WO}_{4} \cdot 2 \mathrm{H}_{2} \mathrm{O}\right), 1 \mathrm{ml} / \mathrm{L}$ trace element solution $(10 \mathrm{ml} / \mathrm{L}$ $\mathrm{HCl} 25 \mathrm{wt} \%, 1.5 \mathrm{~g} / \mathrm{L} \mathrm{FeCl}{ }_{2} \cdot 4 \mathrm{H}_{2} \mathrm{O}, 104 \mathrm{mg} / \mathrm{L} \mathrm{CoCl}_{2}, 82 \mathrm{mg} / \mathrm{L}$ $\mathrm{MnCl}_{2} \cdot 2 \mathrm{H}_{2} \mathrm{O}, 70 \mathrm{mg} / \mathrm{L} \mathrm{ZnCl}, 6 \mathrm{mg} / \mathrm{L} \mathrm{H}_{3} \mathrm{BO}_{3}, 36 \mathrm{mg} / \mathrm{L}$ $\left.\mathrm{Na}_{2} \mathrm{MoO}_{4} \cdot 2 \mathrm{H}_{2} \mathrm{O}, 13 \mathrm{mg} / \mathrm{L} \mathrm{NiCl} 2,1.58 \mathrm{mg} / \mathrm{L} \mathrm{CuCl}_{2}\right), 3 \mathrm{ml} / \mathrm{L}$ vitamin solution $(17 \mathrm{mg} / \mathrm{L}$ vitamin $\mathrm{B} 12,13 \mathrm{mg} / \mathrm{L} 4$ aminibenzoate, $3 \mathrm{mg} / \mathrm{L}$ biotin, $33 \mathrm{mg} / \mathrm{L}$ nicotinic acid, 17 $\mathrm{mg} / \mathrm{L}$ hemicalcium D-pantothenate, $50 \mathrm{mg} / \mathrm{L}$ pyridoxamine$\mathrm{HCl}, 33 \mathrm{mg} / \mathrm{L}$ thiamine- $\mathrm{HCl} \cdot 2 \mathrm{H}_{2} \mathrm{O}, 10 \mathrm{mg} / \mathrm{L} \mathrm{D}, \mathrm{L}-6,8$-thiotic acid, $10 \mathrm{mg} / \mathrm{L}$ riboflavin, $4 \mathrm{mg} / \mathrm{L}$ folic acid), and $0.36 \mathrm{~g} / \mathrm{L}$ glucose. The $\mathrm{pH}$ value of the VL55 media was adjusted to $\mathrm{pH}$ 5.5. To obtain pure cultures of single bacterial strains, AM agar, soil extract agar (medium content and $20 \mathrm{~g} / \mathrm{L}$ agar), and VL55 agar (3\% washed agar) were used for the isolation. 
The 3\% washed agar was prepared as follows: suspended $33 \mathrm{~g}$ agar in $2 \mathrm{~L}$ distilled water and stirred with a magnetic stirrer for about $5 \mathrm{~min}$. Then switch off the stirrer and allowed the agar to settle for $30 \mathrm{~min}$. Decanted off the supernatant and repeated this washing step about 5 times to remove sugar etc. from the agar. Finally, the desired amount of agar was resuspended in $1000 \mathrm{ml}$ of water and autoclaved.

The following chemicals were utilized as effector for the preselection- and microfluid screening experiments: $\mathrm{CuSO}_{4}$. $6 \mathrm{H}_{2} \mathrm{O}, \mathrm{NiSO}_{4} \cdot 6 \mathrm{H}_{2} \mathrm{O}, \mathrm{Co}\left(\mathrm{NO}_{3}\right)_{2} \cdot 6 \mathrm{H}_{2} \mathrm{O}, \mathrm{NaOH}, \mathrm{Na}_{3} \mathrm{VO}_{4}$, $\left(\mathrm{NH}_{4}\right)_{2} \mathrm{CrO}_{7}$ (Merck, Darmstadt, Germany), and $\mathrm{NaCl}$ (VWR, Germany). Eukaryotic translation inhibitor cycloheximide was obtained from BioChemica (Düsseldorf, Germany) in order to prevent growth of soil-derived fungi in droplets. Throughout the dose-response screening experiment, the AM medium was used for the incubation of all isolates. Perfluoromethyldecalin (PP9, F2 Chemicals, Lancashire, UK) was applied as carrier medium for the separation of droplets.

\section{Soil sampling}

Seven soil samples (E18, E27, E81, E83 E88, Q42, and B12) used in this study were collected from ancient copper mining areas and one sample (HBP4) from an archeological excavation. All the sample sites were located in the region of Thuringia and Saxony-Anhalt. The exact locations and a brief description of the soil samples are listed in Table 1.

The archeological soil sample was taken from a medieval waste pit supplying non-ferrous metal artifacts, probably related to a late medieval metal craftsman. Other soil samples (except soil sample HBP4 from the archeological excavation) were taken from the surface of the earth using a sterile falcon tube. Macro fibers and stones were removed and the probes were immediately sealed. Followed by air-drying under sterile conditions (Petri dish) at room temperature to remove excess moisture and water, $1 \mathrm{~g}$ soil was mixed with $15 \mathrm{ml}$ distilled water and vortexed thoroughly. After centrifugation at $200 \times g$ for $20 \mathrm{~min}$, the supernatant was passed through a filter paper to remove excess soil particles and retain bacterial spores and vegetative bacteria. Cycloheximide with a final concentration of $75 \mathrm{mg} / \mathrm{L}$ was added to prevent the growth of soil-derived fungi in droplets.

\section{Cultivation and identification of isolates}

The isolates of $R$. erythropolis from our laboratory collection were used in experiments to determine the tolerance against $\mathrm{Cu}^{2+}, \mathrm{Ni}^{2+}$, and $\mathrm{Co}^{2+}$. R. erythropolis were isolated from various soil samples (see Table 1) with either the droplet-based selection procedure (SS procedure) or the MTP-based diversity exploitation procedure (MTP procedure), which was already described in our previous work [30] (see Fig. 1).

For the preselection SEM, AM and VL55 media with various additions were utilized (detailed information is shown in Table 2). After a defined cultivation time, the reduced communities were applied on agar plates using the streak plate method in order to isolate single bacterial strains. The obtained cultures were characterized by Sanger sequencing after recultivation and successful isolation. The procedure for sample preparation for Sanger sequencing and sequence data analysis was describe in our previous work [30]. We defined that for identification on species level, a percent match of at least $99 \%$ similarity and for identification on genus level, a percent match of at least $97 \%$ are required. The isolate overview is given in Table 2. Finally, these isolates were characterized by highly resolved dose-response screenings against $\mathrm{Cu}^{2+}, \mathrm{Ni}^{2+}$, and $\mathrm{Co}^{2+}$ using microfluid technique.

\section{Microfluidic arrangement}

Details on the fluidic devices, the optical micro devices, and the applied methods for realizing concentration programs as well as achievable accuracy of concentration setting and calculation of the concentrations were reported earlier [31]. Here, a similar experimental setup (Fig. 2) was used for highly resolved concentration-dependent screening of effectors based on a syringe pump with four dosing units (Cetoni $\mathrm{GmbH}$ ). The generation of the droplets was realized through a Peek ${ }^{\mathrm{TM}} 7$ port manifold (Upchurch Scientific, USA) by controlled

Table 1 Soil sample description

\begin{tabular}{lllll}
\hline Sample no. & Location & GPS coordinates (Gauss-Krueger) & Description & Collection date \\
\hline E18 & Hergisdorf & $4463,996 / 5711,089$ & Historic mining area & 24. Mar.2018 \\
E27 & Hettstedt & $4466,585 / 5723,423$ & Historic copper mine & 24.Mar.2014 \\
E81 & Eisleben-Oberhütte & $4468,648 / 5712,696$ & Melting place & 09. May.2016 \\
E83 & Eisleben-Oberhütte & $4468,594 / 5712,73$ & Melting place & 09. May.2016 \\
E88 & Eisleben-Oberhütte & $4469,29 / 5711,667$ & Copper mine & 09. May.2016 \\
HBP4 & Altenburg & $4530,555 / 5649,797$ & Archeological excavation & 15.Aug.2017 \\
B12 & Römhild-Steinsburg & $4399,713 / 5587,157$ & Prehistoric hillfort settlement & $02 . M a y .2017$ \\
Q42 & Uftrungen & $4431,72 / 5707,443$ & Historic mining area & $30 . D e c .2015$ \\
\hline
\end{tabular}




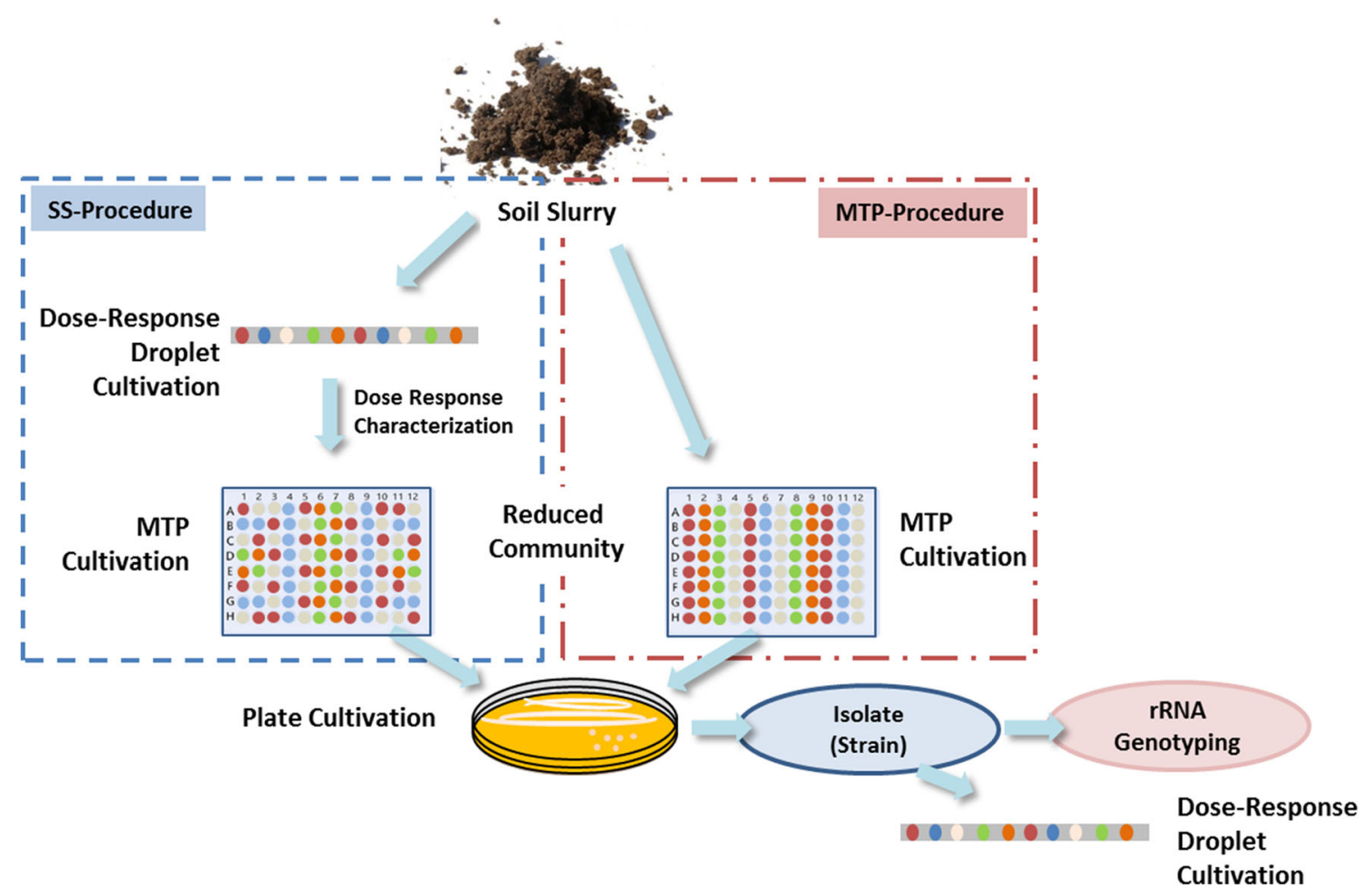

Fig. 1 Selection strategies for identifying heavy metal-tolerant bacteria: droplet-based selection method (SS procedure) and microtiter plate-based procedure (MTP procedure)

dosing of effectors, culture medium, and cell suspension into a flow of carrier medium (perfluoromethyldecalin PP9). The flow rate of the fluid was controlled using a LabVIEWTM program (National Instruments) for the adjustment of concentrations inside the droplets. To investigate the dose-response relationships for single substances, a LabVIEW program with continuous change of the effector concentration was applied (Fig. 2b). The first $20 \mathrm{~s}$ of the control program was set as positive control, followed by a $200 \mathrm{~s}$ concentration gradient program and ended with $5 \mathrm{~s}$ program with $100 \%$ of the effector concentration. The flow rates of the carrier liquid and the cell suspension were set at 136 and $32 \mu \mathrm{L} / \mathrm{min}$. An increasing amount of effector (flow rate from 0 to $32 \mu \mathrm{L} / \mathrm{min}$ ) was compensated by a decreasing amount of cultivation medium (flow rate from 32 to $0 \mu \mathrm{L} / \mathrm{min}$ ). Therefore, the overall flow rate of the droplet generation process was kept constant at 200 $\mu \mathrm{L} / \mathrm{min}$. An initial cell density of 1000 cells per $500 \mathrm{~nL}$ droplet was applied.

The response of the different bacterial strains was characterized by their growth behavior inside the sub-microliter droplets containing the nutrition solution with step-wise varied metal ion concentrations (effectors). The cell densities bevor and after incubation period were determined by microphotometric measurements. Therefore, four microphotometers operated at four different wavelengths have been applied in order to distinguish a possible change in spectral absorption

Table 2 Isolates overview

\begin{tabular}{llllllll}
\hline Isolate no. & Selection procedure & Soil sample & Selection medium & Addition & Conc. of addition & \% Match & Total nucleotides \\
\hline F08 & SS\#2 & E27 & Soil extract & $\mathrm{NiSO}_{4}$ & $2 \mathrm{mM}$ & 99.93 & 1341 \\
F32 & SS\#2 & E81 & AM & $\mathrm{Co}\left(\mathrm{NO}_{3}\right)_{2}$ & $0.5 \mathrm{mM}$ & 100 & 1209 \\
F54 & SS\#2 & E27 & AM & $\mathrm{NiSO}_{4}$ & $1 \mathrm{mM}$ & 100 & 1318 \\
F56 & SS\#5 & hBP4 & Soil extract & $\mathrm{Co}\left(\mathrm{NO}_{3}\right)_{2}$ & $1.5 \mathrm{mM}$ & 100 & 1319 \\
F66 & MTP1 & Q42 & AM & $\mathrm{Na}_{3} \mathrm{VO}_{4}$ & $1 \mathrm{mM}$ & 99.92 & 1332 \\
F143 & MTP3 & E83 & VL55 & $\mathrm{NaCl}_{2}$ & $500 \mathrm{mM}$ & 99.92 & 1219 \\
F146 & MTP3 & E88 & VL55 & $\mathrm{NaOH}_{2}$ & $20 \mathrm{mM}$ & 99.93 & 1356 \\
F150 & MTP3 & E88 & VL55 & $\mathrm{Na}_{3} \mathrm{VO}_{4}$ & $1 \mathrm{mM}$ & 99.45 & 1280 \\
F165 & MTP3 & E18 & VL55 & $\mathrm{Na}_{3} \mathrm{VO}_{4}$ & $1 \mathrm{mM}$ & 100 & 1059 \\
F357 & MTP7 & B12 & AM & $\left(\mathrm{NH}_{4}\right)_{2} \mathrm{CrO}_{7}$ & $0.1 \mathrm{mM}$ & 100 & 1272 \\
\hline
\end{tabular}



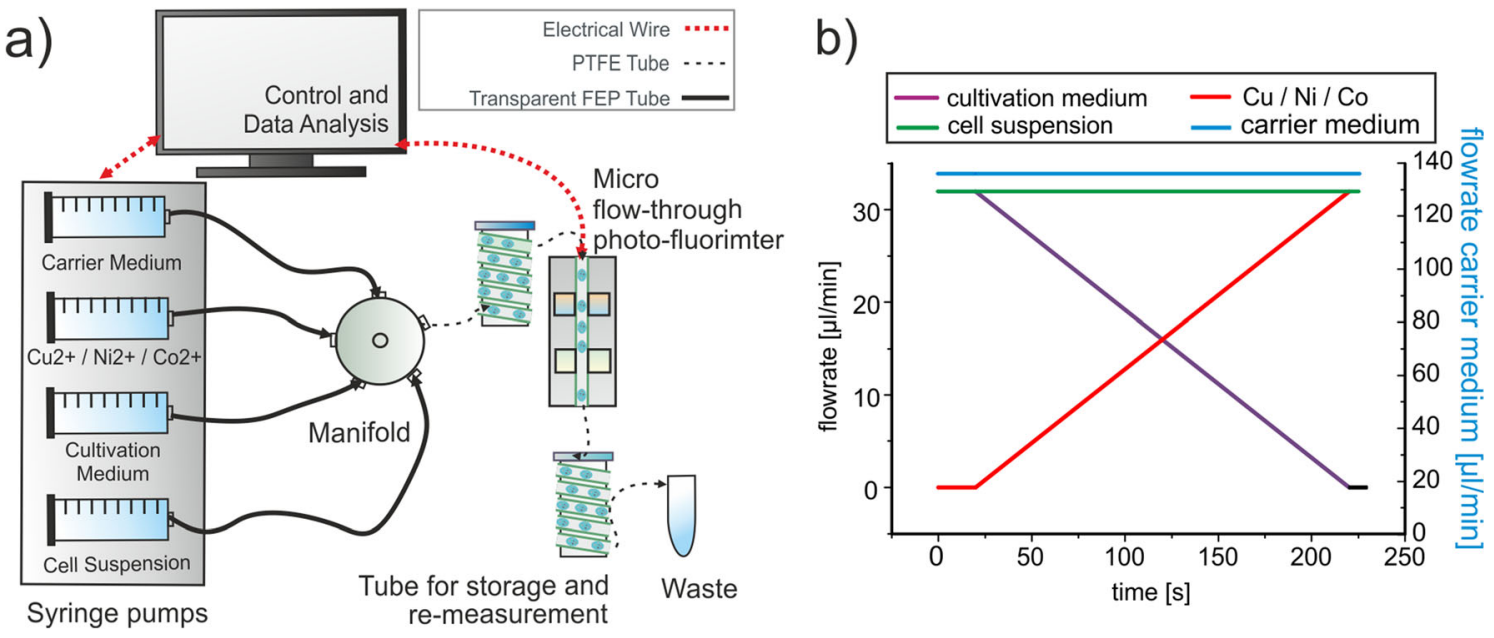

Fig. 2 a Microfluidic setup for highly resolved dose-response screenings. b LabVIEW control program for the generation of concentration gradients

and to separate it from light scattering due to an increase of cell density by growth. In addition, a microfluorimetry was applied in order to detect changes in physiological activity by the cellular autofluorescence and to check stimulating effects of increasing metal concentration in the sub-lethal range on the production of fluorescing metabolites. The evidence of growth during incubation and its intensity was identified by comparing the photometric as well as the fluorometric signals from each individual droplet before and after incubation. Every decrease in transmitted light and every increase in fluorescence intensity indicate bacterial growth. No changes of these signals in case of high metal ion concentrations indicate the suppression of bacterial growth.

For the optical measurements of complete sequences, each droplet is transported with constant flow rate through the optical detector unit transported with constant flow rate through an optical detector unit containing flow-through photometer and fluorometer, which measures the droplet directly through the FEP tubing (Fig. 2a). Four light emitting diodes (Agilent, USA) with peak wavelengths of 470, 505, 615, and $660 \mathrm{~nm}$ with a spectral half-width about $30 \mathrm{~nm}$ were used for the scattering measurement. For monitoring bacterial autofluorescence, a laser diode with a peak wavelength of $405 \mathrm{~nm}$ with a bandwidth of $\pm 5 \mathrm{~nm}$ (Changchun New Industries Optoelectronis, China) was used with a combination of a short-pass $(455 \mathrm{~nm})$ and long-pass filters $(510 \mathrm{~nm})$ (Laser Components, Germany). The emitted photons were counted by photomultiplier modules (Hamamatsu, Japan). The tube coils with rolled Teflon tubes (PTFE) with a length of $4 \mathrm{~m}$ ( $0.5 \mathrm{~mm}$ ID, $1.0 \mathrm{~mm}$ OD) were used to store and to incubate (at $22{ }^{\circ} \mathrm{C}$ ) the generated sequences. In total, the experiments were repeated two times and for each sequence, we analyzed about 350 droplets. In addition, negative controls (droplet sequence against effector without cells) were always performed in parallel to include them for obtaining optical reference measurements for each experimental run.

\section{Results and discussions}

The experimental concept is based on the droplet-based microfluid technology. Between several hundred and a few thousand of droplets are generated in a well-defined sequential order inside a micro PTEF or FEP tube. The input is represented by a sequence of droplets each containing the same cell density but different concentration of the effectors to be investigated. The response of cell cultures inside droplets was evaluated by two independent optical measurements, which supplies two sets of complementary information about the evolution and activity of bacteria. The total of final cell number is well reflected by the reduction of the intensity of transmitted light by use of micro flow-through photometer. This method gives information on the cumulative number of cell divisions, but it does not allow to distinguish between vital and dead cells. A certain measure for the viability is given by the endogenous cellular autofluorescence activity cause of a micro flow-through fluorimeter. In principle, different molecular species can contribute to the autofluorescence of bacteria. Different species are marked by different features of fluorescence spectra which can be used for empirically distinguishing them [32]. Currently, it is not possible to draw a closed picture of the causality of heavy metal stress on the autofluorescence response of bacterial strains. Nevertheless, two mechanisms for the influence of metals on autofluorescence are conceivable. One is the inclusion of metal ions into fluorophores for example by complex formation - which leads to enhanced spectral absorption fluorescence quantum yields. Another mechanism is the induction of molecular stress and the increased concentration of stress-indicating molecules with fluorescence activity. In principle, a significant contributions to autofluorescence could originate from tryptophan or from $\mathrm{NAD}(\mathrm{P}) \mathrm{H}$ [33], but this fluorescence is excited in UV, because the absorption in the visible range can be neglected. Among the candidates for enhanced autofluorescence by 
visible light, flavin and its compounds are the most probable molecular species. These compounds play an important role in redox processes, in detoxification, as well as in the generation and reduction of oxidative stress [34]. The emission maxima around $500 \mathrm{~nm}$ are in good agreement with the enhanced autofluorescence intensities detected in case of sub-lethal stress in the cultivation experiments and could be interpreted as metal ion-induced increase in flavin species. Obviously, this reaction on the heavy metal stress is not only dependent on type and concentration of metal ions but also varies from strain to strain within the one investigated species.

Microorganisms that occur in biotopes with elevated heavy metal concentrations often have special resistance mechanisms to the respective metals that prevent or significantly reduce the damage caused by the toxic element. The possible mechanisms of heavy metal resistance are: (i) complexation of heavy metal ions, i.e., to bind specifically and thus prevent heavy metal ions from binding in an uncontrolled manner to nucleic acids and proteins or contributing to the generation of free radicals [35], (ii) removal of heavy metal ions by efflux transporters [36], (iii) enzymes for detoxification of highly reactive oxygen species [37], and (iv) reduction of the toxicity of a heavy metal by changing its valence [38].

\section{Dose-response screening against $\mathrm{CuSO}_{4}, \mathrm{NiSO}_{4}$, and $\mathrm{Co}\left(\mathrm{NO}_{3}\right)_{2}$ of two $\mathrm{R}$. erythropolis strains isolated from one soil sample}

Soil slurry from soil E27 was inoculated together with increasing concentrations of nickel and copper into droplets by using $\mathrm{AM}$ and soil extract medium. After 35 days incubation inside droplets, F08 was isolated from the well with soil extract medium in combination with $2 \mathrm{mM} \mathrm{Ni}^{2+}$. F54 was isolated from AM medium in combination with $1 \mathrm{mM}$ nickel stress (see Table 2). Both R. erythropolis strains isolated from soil samples E27 were compared for their behavior with respect to addition of copper, nickel, and cobalt to the nutrition medium. The results are reflected by microphotometric (Fig. 3a, c, e) and microfluorometric measurements (Fig. 3b, d, f). Each dot in the graphs represents the optical signal of one droplet of a volume of about $0.5 \mu \mathrm{L}$. The measurement beam has a diameter of about $0.5 \mathrm{~mm}$, which corresponds to the complete internal diameter of the micro tube. The integration of optical signal over the complete residence time of the droplet ensures the registration of a representative optical signal for each individual cultivation volume. The averaging over the entire droplet is additionally supported by the transport-induced circular droplet-internal convection of the liquid inside the droplets. All measurement values of one graph were obtained in one single experimental run, so that all droplets experienced exactly the same conditions and procedures.

As results, the optical density and the fluorescence of droplets change similarly with the increase of metal ion concentration and all isolates show a similar response for all three metal ions (Fig. 3). This speaks for the fact that both signals reflect mainly the density of cells inside single droplets and the dependency of bacterial growth on metal ion concentration. In the case of $\mathrm{Ni}^{2+}$, an unaffected growth at low concentrations of up to $0.3 \mathrm{mM}$ and a moderate growth between 0.3 and $2.1 \mathrm{mM} \mathrm{Ni}^{2+}$ (Fig. 3e, f) was observed. This intermediate response is clearly separated from the unaffected growth at low concentrations and total inhibition at higher metal concentrations and was observed for both strains. A similar behavior to nickel was found in the presence of copper; three different types (intensive growth, limited growth, and growth inhibition) of growth responses with respect to different concentration ranges were observed for all strains. The unaffected growth of F08 was located at $0.25 \mathrm{mM}$, while F54 was found at $0.12 \mathrm{mM} \mathrm{Cu}^{2+}$. Above $0.25 \mathrm{mM} \mathrm{Cu}^{2+}$ of $\mathrm{F} 08$, the autofluorescence intensity was significantly reduced with only $5 \%$ intensity compared to the droplets with less than $0.25 \mathrm{mM}$ $\mathrm{Cu}^{2+}$. The same step-wise response was also observed by F54. It was found that the critical value for $\mathrm{Cu}^{2+}$ of F54 (1.5 $\mathrm{mM})$ was about $10 \%$ lower than F08 $\left(1.7 \mathrm{mM} \mathrm{Cu}^{2+}\right)$.

Much lower metal tolerance of all strains was evidenced when cobalt ions were applied. Compared to nickel and copper, with increasing cobalt concentration, a significant and sharp transition between growth and growth inhibition was found. A total inhibition at $0.5 \mathrm{mM} \mathrm{Co}^{2+}$ was determined for both isolates. While copper and nickel are essential for many different enzymes, cobalt is necessary for the function of only a limited number of enzymes and results for a generally higher sensitivity and a less developed homeostasis and storage characteristics for this metal.

The comparison of the responses of the isolates F08 and F54 on three metals indicated that both $R$. erythropolis could be originating from the same strain in the soil sample. This interpretation was in coordination with 16S rRNA results determining 99.93 and $100 \%$ similarity between the strains.

\section{Response during cobalt stress of $R$. erythropolis strains isolated from different soil samples}

Different $R$. erythropolis isolates could be compared by their highly resolved dose-response patterns obtainable through concentration-dependent microsegmented flow cultivation. These patterns were shown for eight isolates. The growth was evaluated after $8-13$ days of cultivation by measuring the autofluorescence intensity at $405 \mathrm{~nm}$ utilizing the microfluorometry. As a result, it was observed that all strains differed considerably in the critical cobalt concentration as well as in the average autofluorescence activity below the critical concentration (Fig. 4). Whereas F32, F54, F66, F143, F150, F165, and F357 appeared to have a comparatively low $\mathrm{Co}^{2+}$ tolerance $(0.25-0.9 \mathrm{mM})$, the strain F56 showed a 

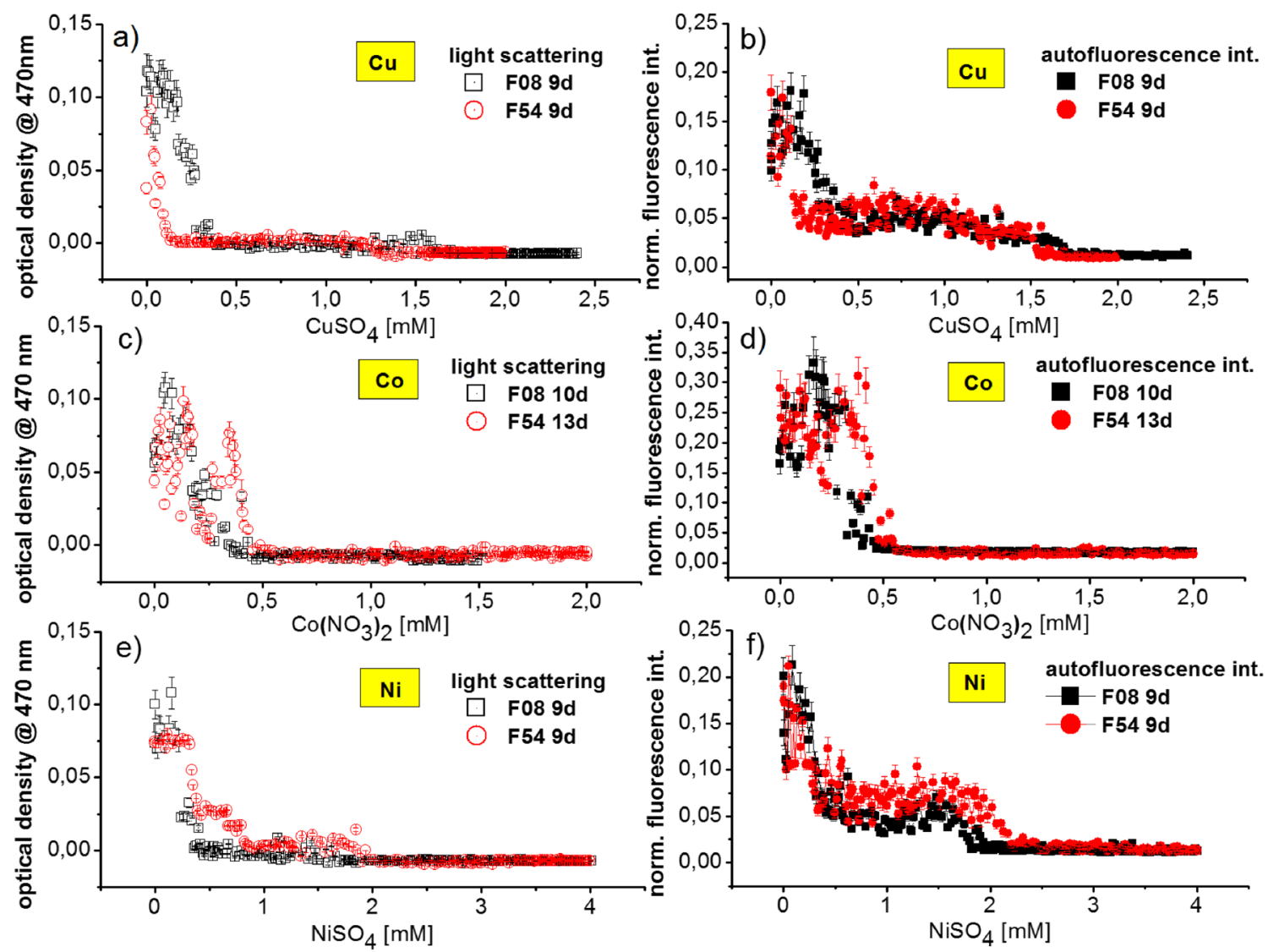

Fig. 3 Comparison of highly concentration-resolved dose-response functions of two R. erythropolis isolates F08 (square), F54 (circle). Both strains were inoculated together with increasing concentrations of copper $(\mathbf{a}, \mathbf{b})$, cobalt $(\mathbf{c}, \mathbf{d})$, and nickel $(\mathbf{e}, \mathbf{f})$ into $500 \mathrm{~nL}$ droplets. Extinction at

$470 \mathrm{~nm}$ excitation (a, c, e) and fluorescence at 405/425 nm excitation/ emission $(\mathbf{b}, \mathbf{d}, \mathbf{f})$ from the $R$. erythropolis in the droplets were measured by micro flow-through sensing after 9 to 13 days incubation. Every dot represents one droplet

significant reduction of fluorescence only above a concentration of $36 \mathrm{mM} \mathrm{Co}^{2+}$ (Fig. 4).

The highly resolved dose-response functions of Fig. $4 \mathrm{a}$ show a normal growth occurred at up to $0.45 \mathrm{mM} \mathrm{Co}^{2+}$ and a total inhibition of growth was observed above $0.9 \mathrm{mM}$ for the strain $\mathrm{F} 32$. With an increasing concentration of $\mathrm{Co}^{2+}$ between 0.45 and $0.9 \mathrm{mM}$, the autofluorescence intensity gradually decreased. A comparatively steep transition between full growth and suppression was observed in case of F54, F56, F150, and F165 against $\mathrm{Co}^{2+}$. The following strains evidenced a lower cobalt tolerance: F66 and F165 were totally inhibited at $0.3 \mathrm{mM}, \mathrm{F} 150$ at $0.35 \mathrm{mM}$, and F357 at $0.25 \mathrm{mM}$ (Fig. 4d, f, g, h).

The observed low autofluorescence after the incubation indicates a low concentration of cells in the droplets in case of the isolate F143 from soil sample E83 at low cobalt concentrations. It is probably caused by a slow growth rate of the bacteria colonies inside the droplets during the incubation period. F143 was significantly stimulated at sub-lethal doses of $\mathrm{Co}^{2+}$ (above $0.85 \mathrm{mM}$ ). The autofluorescence rose up to considerably higher values (about $300 \%$ ). The high resolution revealed a strict transition between this highly stimulated

growth and complete suppression at a $\mathrm{Co}^{2+}$ concentration of $1 \mathrm{mM}$ (Fig. 4e). F357 showed similar, but not identical, growth behavior. A pronounced stimulatory effect at sublethal doses of $\mathrm{Co}^{2+}$ at about $0.15 \mathrm{mM}$ was observed for strain F357 (Fig. 4h).

Certain specificity was found in the sub-lethal range of strain F56. Between 0 and $20 \mathrm{mM} \mathrm{Co}^{2+}$, the fluorescence of single droplets turned out to be more scattering when the cobalt concentration increases. This behavior can be interpreted as a consequence of the stochastic confinement effect due to the small cultivation volumes. The developing bacterial populations in single droplets responded individually to the increase of cobalt concentration. Some of them show a significantly reduced autofluorescence, other responds with a considerable enhancement of fluorescence activity. The range between 20 and $35 \mathrm{mM}$ is marked by a lowering in autofluorescence and a lower scattering rate on individual responses. It seems that the moderate cobalt stress leads to the differentiation of individual responses of the small start populations inside droplets. It can be summarized that F56 is a highly cobalttolerant strain. Bacterial cells and small populations of this strain react with an increasing spectral width of physiological 

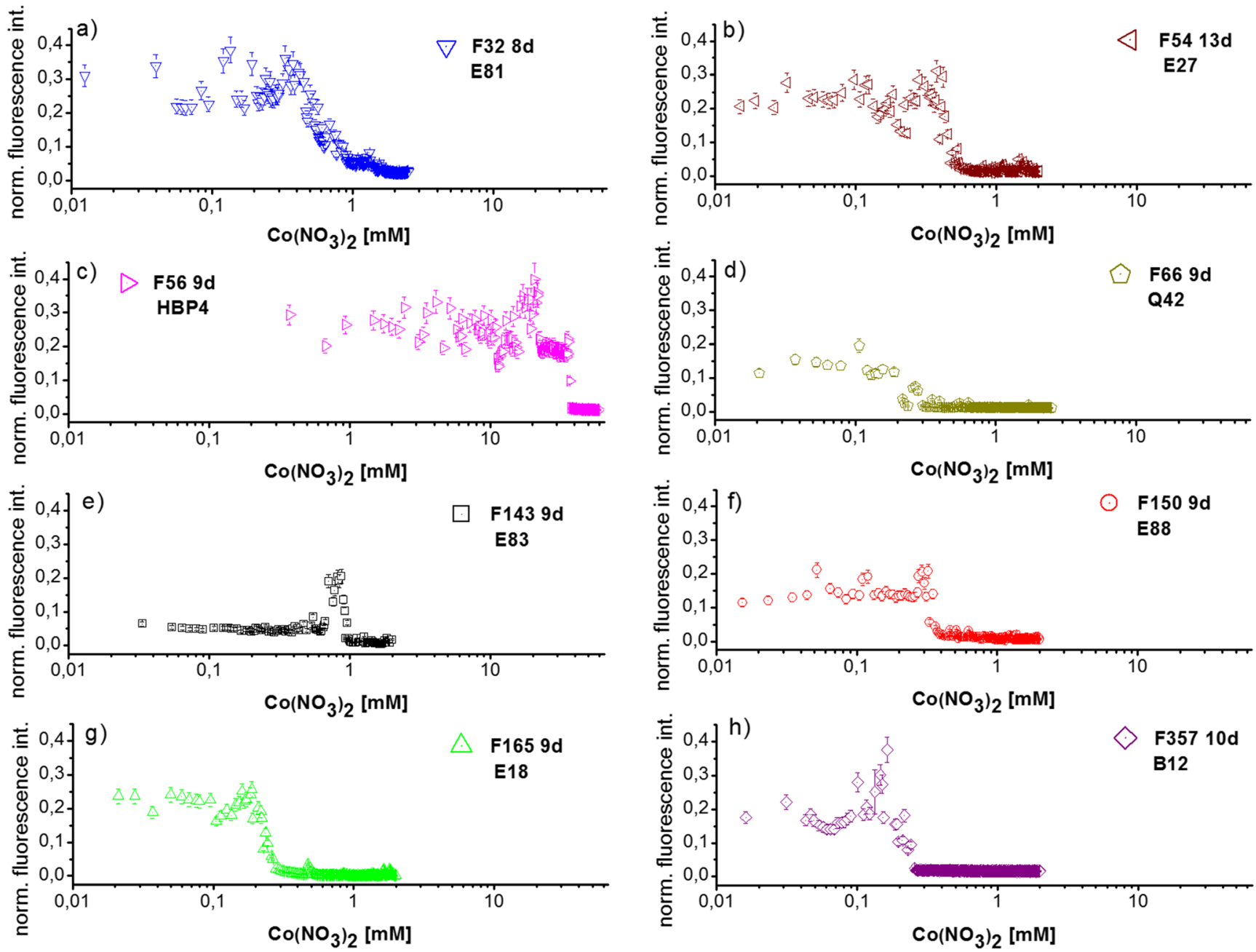

Fig. 4 Fluorometric data from concentration-dependent microfluidic screening for the response of $R$. erythropolis isolates obtained from eight soil samples on $\mathrm{Co}^{2+}$ stress (see Tables 1 and 2 for origin of samples)

activity on the increasing cobalt stress over a large concentration range.

\section{Correlation of $\mathrm{Cu}^{2+} / \mathrm{Ni}^{2+}$ and $\mathrm{Co}^{2+} / \mathrm{Ni}^{2+}$ tolerance as a function of the origin of the soil samples}

The correlation of the total inhibition value of all ten separately isolated $R$. erythropolis strains against $\mathrm{CuSO}_{4}, \mathrm{NiSO}_{4}$, and $\mathrm{Co}\left(\mathrm{NO}_{3}\right)_{2}$ shows a strong relation to the origin of the isolates. Despite the fact that the number of investigated samples and isolated strains are limited, the distribution of critical concentrations of the both displayed metal ions lead to remarkable differences. The narrow values for F08, F54, and F123 (red circle) confirm that the isolates are representing the same strain from soil sample E27 (see Table 2). Further, it is remarkable that the isolates F32, F143, F146, and F150 (blue triangle) are relatively close together, but less strongly connected to each other as the isolates F08, F54, and F123 from soil sample E27. These cultures have been isolated from three different soil samples, which have been taken in one area near
Eisleben-Oberhütte, a former copper smelting area. F66 and F164 (black square), which came from more distant sampling sites (ancient mining places near Hergisdorf and near Uftrungen), show lower copper tolerances. The most important difference was observed between the sample from the archeological excavation (hBP4, medieval city of Altenburg, East Thuringia) and all other samples concerning the tolerance against cobalt ions (purple triangle). Whereas for all other samples critical thresholds between about 0.1 and $1 \mathrm{mM}$ against $\mathrm{Co}^{2+}$ have been found, the isolate $\mathrm{F} 56$ from sample hBP4 shows a very high tolerance threshold of about $40 \mathrm{mM}$ $\mathrm{Co}^{2+}$. At the same time, this strain is also marked by significant higher tolerance against $\mathrm{Ni}^{2+}$ (Fig. 5). In contrast, the isolate F357 (green triangle) is marked by a significant lower nickel tolerance in comparison with the other strains originating from the copper mining region.

The importance of the sample origins became much clear after including critical values of copper ion concentration. The comparison of copper tolerances confirms the special characteristics of the strain isolated from the Römhild-Steinsburg 
sample F357 (green triangle) with low $\mathrm{Cu}^{2+}$ and low $\mathrm{Ni}^{2+}$ tolerance (Fig. 5a). This specific character can be understood by the character of the place, what means from the surface of an area which is given-off as a settlement place more than 2000 years ago and now in a forest-covered protected natural area. In contrast to that, F56 is not originating from a surface sample, but from a buried cultural soil from an intensively used urban settlement area, and all other samples are originating from earlier copper mining and smelting places. These circumstances make plausible that all these isolated strains are marked by a significant higher $\mathrm{Cu}^{2+}$ tolerance than the strain F357. Thus, the correlation plots indicate R. erythropolis strains with different similarities from a phenotype point of view (Fig. 5). Obviously, the tolerance values for the different strains reflect the phenotypic divergence of $R$. erythropolis from the different places and regions.

The results are encouraging for future investigations of larger quantities of isolates from different places, on the one hand, to improve the statistical relevance of the site-dependent response of soil bacterial strains of the same species and also to pronounce the requirement of a broader screening of soils for assessing diversity in the response of soil bacterial communities with different place histories.

\section{Conclusions}

The investigation shows that the highly resolved doseresponse data obtained by microfluidic cultivation studies are well suited for characterizing the response of different strains of the soil bacterium $R$. erythropolis and for distinguishing different susceptibilities of strains of this species from different sample sites. Characteristic highly resolved dose-response functions have been obtained for all ten isolates
R. erythropolis strains and for the three investigated metals copper, nickel, and cobalt by the microfluidic screenings. These response functions supply the metal ion concentrations for total inhibition. In addition, they reflect transitions between fast growth and reduced growth of bacteria in dependence of metal ion concentrations, in some cases. The high number of individual small test volumes in each screening run allows further to identify non-monotonous changes in the concentration-dependent growth and activity behavior as the formation of sub-lethal peaks in the dose-response functions. They are found, in particular, in the autofluorescence signals from droplets with metal concentrations in the sub-lethal range. Their appearance differs strongly for the different strains and metals.

An essential result of the investigation is the finding that differences in the heavy metal susceptibility of the various strains are related to the special local situation and differences of the character of sampling sites, although both investigated strains have nearly identical 16S rRNA sequences, which are 99.93 and $100 \%$ matching the known sequence of the species $R$. erythropolis. It can be concluded that two isolates, which had been obtained by different cultivation procedures from one soil sample (F08, F54), represent one strain, which could be concluded from the very similar observed critical metal ion concentrations. In contrast, these strains are significantly distinguishable from isolates of soil samples from other places. Particularly large differences exist between the critical concentrations of the soil samples from the ancient East Harz copper mining region and a sample from an archeological excavation of Altenburg, which was indicated from a soil which had been covered by soil and undisturbed stored since the Middle Ages. Our study showed that microfluidic screenings are useful for the empirical characterization based on the susceptibility of different strains on three selected heavy
Fig. 5 Correlation diagram of $\mathbf{a}$

$\mathrm{Ni}^{2+}$ and $\mathrm{Cu}^{2+}$ and $\mathbf{b} \mathrm{Co}^{2+}$ and

$\mathrm{Ni}^{2+}$ tolerance of ten

R. erythropolis strains isolated from different origin of the soil samples. Data based on the autofluorescence intensity measured by micro flow fluorometer after 9-11 days incubation inside droplet
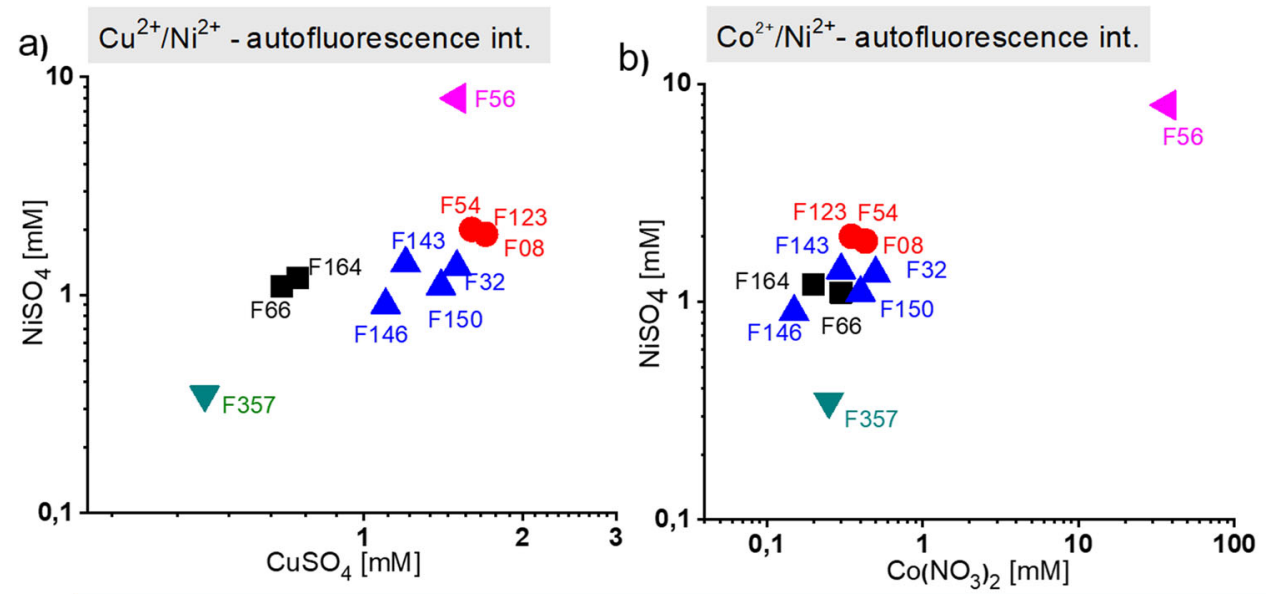

soil sample information

Uftrungen, historic mining area

Eisleben-Oberhütte, melting place

$\checkmark$ Römhild-Steinsburg, prehistoric hillfort settlement
Hettstedt, historic copper mining area Altenburg, archaeological excavation 
metals. Further confirms that the response of strains isolated at various sites can be distinguished from each other. However, a complete characterization of genetic and physiologic differences of isolated strains cannot solely be based on the $16 \mathrm{~S}$ rRNA sequence similarity [39]. Thus, further phenotypic characterization and whole genome sequencing should be considered in the future.

In summary, it can be concluded that the highly resolved dose-response functions from microsegmented flow cultivation are very powerful for evaluating the responsivity of local bacteria strains of the same species against components of environmental pollution. The microfluidic strategy is very promising for empirical characterization of soil bacterial strains from special places with different human activities in the past. Furthermore, this technical approach could be utilized in the future to isolate new strains with enhanced potential for growing in contaminated areas, for bioremediation, and for characterizing the ecological value of soil organisms, in general.

Supplementary Information The online version contains supplementary material available at https://doi.org/10.1007/s42770-021-00495-2 .

Acknowledgements We thank Erika Kothe (University Jena) and Karin Martin, Martin Roth (HKI Jena) for stimulating discussions and collaboration on miniaturized screenings for soil bacteria. We thank Lars Hafermann for the EDX measurement and Frances Möller for the lab assistant. The financial support within the frame of the German Federal Ministry of Education and Research project Bactocat (Kz. 031A161A) and Development Bank Thuringia project Screen $\mid$ in drop lines (Kz. 2016FE9016) are gratefully acknowledged. Open Access funding enabled and organized by Projekt DEAL.

Author contribution J. Cao and M. Köhler contributed equally to this work. M. Köhler designed the study. J. Cao, C. Chande, and F. Kalensee optimized the protocol. T. Schüler and M. Köhler performed soil sampling. C. Chande and F. Kalensee performed the bacterial isolation and identification. J. Cao performed the microfluidic screening experiments. J. Cao and M. Köhler contributed in analysis of data and wrote the manuscript. C. Chande and T. Schüler assisted in interpreting analysis of the data and discussions. All authors read and edited the manuscript.

Data availability The data used to support the findings of this study are available from the corresponding author upon request.

\section{Declarations}

Competing interests The authors declare no competing interests.

Open Access This article is licensed under a Creative Commons Attribution 4.0 International License, which permits use, sharing, adaptation, distribution and reproduction in any medium or format, as long as you give appropriate credit to the original author(s) and the source, provide a link to the Creative Commons licence, and indicate if changes were made. The images or other third party material in this article are included in the article's Creative Commons licence, unless indicated otherwise in a credit line to the material. If material is not included in the article's Creative Commons licence and your intended use is not permitted by statutory regulation or exceeds the permitted use, you will need to obtain permission directly from the copyright holder. To view a copy of this licence, visit http://creativecommons.org/licenses/by/4.0/.

\section{References}

1. Hou DY, Al-Tabbaa A (2014) Sustainability: a new imperative in contaminated land remediation. Environ Sci Policy 39:25-34. https://doi.org/10.1016/j.envsci.2014.02.003

2. Le Borgne S, Quintero R (2003) Biotechnological processes for the refining of petroleum. Fuel Process Technol 81(2):155-169. https:// doi.org/10.1016/S0378-3820(03)00007-9

3. Hu TL (2003) Color removal ability of a streptomycin resistant decolorizing strain Rhodococcus erythropolis (ATCC 4277.1). Water Sci Technol 47(10):169-174

4. Buthelezi SP, Olaniran AO, Pillay B (2012) Textile dye removal from wastewater effluents using bioflocculants produced by indigenous bacterial isolates. Molecules 17(12):14260-14274. https:// doi.org/10.3390/molecules171214260

5. Sandhu A, Halverson LJ, Beattie GA (2009) Identification and genetic characterization of phenol-degrading bacteria from leaf microbial communities. Microb Ecol 57(2):276-285. https://doi.org/ 10.1007/s00248-008-9473-9

6. Häggblom MM, Janke D, Salkinoja-Salonen MS (1989) Transformation of chlorinated phenolic compounds in the genus Rhodococcus. Microb Ecol 18(2):147-159. https://doi.org/10. 1007/bf02030123

7. Kurane R, Tomizuka N (1992) Towards new-biomaterial produced by microorganism-bioflocculant and bioabsorbent. Nippon Kagaku Kaishi 5:453-463

8. Stancu MM (2015) Response of Rhodococcus erythropolis strain IBBPo1 to toxic organic solvents. Braz J Microbiol 46(4):10091018. https://doi.org/10.1590/S1517-838246420140462

9. Russel M, Li X, Qu M, Wu M, Liu L, Alam MM (2019) Exploring the novel indigenous strains for degrading the crude oil contaminants in soil sample. Int J Environ Sci Technol 16(10):5657-5668

10. Gupta N, Roychoudhury PK, Deb JK (2005) Biotechnology of desulfurization of diesel: prospects and challenges. Appl Microbiol Biotechnol 66(4):356-366

11. Ohkuma M (2003) Termite symbiotic systems: efficient biorecycling of lignocellulose. Appl Microbiol Biotechnol 61(1):1-9

12. de Carvalho CCCR (2012) Adaptation of Rhodococcus erythropolis cells for growth and bioremediation under extreme conditions. Res Microbiol 163(2):125-136. https://doi.org/10. 1016/j.resmic.2011.11.003

13. Tsuruta $\mathrm{T}$ (2004) Cell-associated adsorption of thorium or uranium from aqueous system using various microorganisms. Water Air Soil Pollut 159(1-4):35-47. https://doi.org/10.1023/B:WATE. 0000049190.05993.3b

14. Banerjee S, Joshi SR, Mandal T, Halder G (2017) Insight into Cr6+ reduction efficiency of Rhodococcus erythropolis isolated from coalmine waste water. Chemosphere 167:269-281. https://doi.org/ 10.1016/j.chemosphere.2016.10.012

15. Pereira SIA, Barbosa L, Castro PML (2015) Rhizobacteria isolated from a metal-polluted area enhance plant growth in zinc and cadmium-contaminated soil. Int J Environ Sci Technol 12(7): 2127-2142. https://doi.org/10.1007/s13762-014-0614-z

16. Banat IM, Franzetti A, Gandolfi I, Bestetti G, Martinotti MG, Fracchia L, Smyth TJ, Marchant R (2010) Microbial biosurfactants production, applications and future potential. Appl Microbiol Biotechnol 87(2):427-444

17. Rosenberg E, Ron EZ (1999) High- and low-molecular-mass microbial surfactants. Appl Microbiol Biotechnol 52(2):154-162 
18. de Carvalho CCCR, da Fonseca MMR (2006) Biotransformation of terpenes. Biotechnol Adv 24(2):134-142

19. Donova MV, Egorova OV (2012) Microbial steroid transformations: current state and prospects. Appl Microbiol Biotechnol 94(6):1423-1447

20. Tyagi M, da Fonseca MMR, de Carvalho CCCR (2011) Bioaugmentation and biostimulation strategies to improve the effectiveness of bioremediation processes. Biodegradation 22(2): 231-241. https://doi.org/10.1007/s10532-010-9394-4

21. Zheng B, Tice JD, Ismagilov RF (2004) Formation of droplets of in microfluidic channels alternating composition and applications to indexing of concentrations in droplet-based assays. Anal Chem 76(17):4977-4982

22. Kohler JM, Henkel T, Grodrian A, Kirner T, Roth M, Martin K, Metze J (2004) Digital reaction technology by micro segmented flow-components, concepts and applications. Chem Eng J 101(1-3):201-216

23. Funfak A, Cao J, Wolfbeis O, Martin K, Kohler J (2009) Monitoring cell cultivation in microfluidic segments by optical $\mathrm{pH}$ sensing with a micro flow-through fluorometer using dyedoped polymer particles. Microchim Acta 164(3-4):279-286. https://doi.org/10.1007/s00604-008-0096-0

24. Cao JL, Kursten D, Krause K, Kothe E, Martin K, Roth M, Kohler JM (2013) Application of micro-segmented flow for twodimensional characterization of the combinatorial effect of zinc and copper ions on metal-tolerant Streptomyces strains. Appl Microbiol Biotechnol 97(20):8923-8930. https://doi.org/10.1007/ s00253-013-5147-8

25. Cao JL, Lars H, Köhler MJ (2017) Stochastically reduced communities - microfluidic compartments as model and investigation tool for soil microorganism growth in structured spaces. Eng Life Sci 17:792-800. https://doi.org/10.1002/elsc.201600264

26. Kursten D, Moller F, Gross GA, Lenk C, Visaveliya N, Schuler T, Kohler JM (2015) Identification of response classes from heavy metal-tolerant soil microbial communities by highly resolved concentration-dependent screenings in a microfluidic system. Methods Ecol Evol 6(5):600-609. https://doi.org/10.1111/2041210x.12344

27. Kursten D, Cao JL, Funfak A, Muller P, Kohler JM (2011) Cultivation of Chlorella vulgaris in microfluid segments and microtoxicological determination of their sensitivity against $\mathrm{CuCl} 2$ in the nanoliter range. Eng Life Sci 11(6):580-587. https:// doi.org/10.1002/elsc. 201100023

28. Funfak A, Brosing A, Brand M, Kohler JM (2007) Micro fluid segment technique for screening and development studies on
Danio rerio embryos. Lab Chip 7(9):1132-1138. https://doi.org/ 10.1039/b701116d

29. Alisi C, Musella R, Tasso F, Ubaldi C, Manzo S, Cremisini C, Sprocati AR (2009) Bioremediation of diesel oil in a cocontaminated soil by bioaugmentation with a microbial formula tailored with native strains selected for heavy metals resistance. Sci Total Environ 407(8):3024-3032

30. Cao J, Kalensee F, Günther PM, Köhler JM (2020) Microsegmented flow-assisted miniaturized culturing for isolation and characterization of heavy metal-tolerant bacteria. Int J Environ Sci Technol 17(1):1-16

31. Cao JL, Kursten D, Schneider S, Knauer A, Gunther PM, Kohler JM (2012) Uncovering toxicological complexity by multidimensional screenings in microsegmented flow: modulation of antibiotic interference by nanoparticles. Lab Chip 12(3):474-484. https://doi.org/10.1039/c1lc20584f

32. Sorrell MJ, Tribble J, Reinisch L, Werkhaven JA, Ossoff RH (1994) Bacteria identification of otitis media with fluorescence spectroscopy. Lasers Surg Med 14(2):155-163. https://doi.org/10. 1002/1096-9101(1994)14:2<155::aid-1sm1900140208>3.0.co;2-1

33. Huang S, Heikal AA, Webb WW (2002) Two-photon fluorescence spectroscopy and microscopy of $\mathrm{NAD}(\mathrm{P}) \mathrm{H}$ and flavoprotein. Biophys J 82(5):2811-2825. https://doi.org/10.1016/S00063495(02)75621-X

34. Massey V (2000) The chemical and biological versatility of riboflavin. Biochem Soc Trans 28(4):283-296

35. Schmidt A, Schmidt A, Haferburg G, Kothe E (2007) Superoxide dismutases of heavy metal resistant streptomycetes. J Basic Microbiol 47(1):56-62

36. Nies DH (2003) Efflux-mediated heavy metal resistance in prokaryotes. FEMS Microbiol Rev 27(2-3):313-339

37. Haferburg G, Kothe E (2010) Metallomics: lessons for metalliferous soil remediation. Appl Microbiol Biotechnol 87(4):1271-1280

38. Polti MA, Amoroso MJ, Abate CM (2007) Chromium(VI) resistance and removal by actinomycete strains isolated from sediments. Chemosphere 67(4):660-667

39. Xu JL, He J, Wang ZC, Wang K, Li WJ, Tang SK, Li SP (2007) Rhodococcus qingshengii sp nov., a carbendazim-degrading bacterium. Int J Syst Evol Microbiol 57:2754-2757. https://doi.org/10. 1099/ijs.0.65095-0

Publisher's note Springer Nature remains neutral with regard to jurisdictional claims in published maps and institutional affiliations. 